\title{
High-Temperature Corrosion of Cast Iron in Sulfur Vapor*
}

\author{
Keizo NisHIDA**
}

Introduction : The sulfurization of cast iron has been often reported, but these contained mainly the results obtained under $\mathrm{H}_{2} \mathrm{~S}$ atmosphere(1). Meanwhile, the resistance of cast iron against sulfur attack was found to be much modified by adding aluminum ${ }^{(2)}$. The details of the sulfide scale grown on iron and steel surface are not known except in our recent paper on the scale grown in sulfur smelting $\operatorname{pots}^{(3)}$.

The main constituents in the scale of cast iron change their concentrations periodically with changing position, and the scale consists of two layers. In the inner layer, there exists graphite flake and the change of lattice parameters is conspicuous.

The experiment was carried out on the corrosion of two kinds of cast iron, one containing $3.62 \% \mathrm{Al}$ (named Al-C.I.) and the other being usual one (named M.C.I.) which showed the mottled structure.

Experimental method: Test pieces of $20 \times 5 \times 10 \mathrm{~mm}$ prepared from these two kinds of cast iron were exposed in sulfur vapor at $460 \sim 900^{\circ} \mathrm{C}$ and $1 \sim 12 \mathrm{hrs}$. under $1 \mathrm{~atm}$. by the same apparatus as shown in the previous paper ${ }^{(4)}$. Then their cross-sections were examined.

Results and Discussion: (a) The Thickness of Sulfide Scale. Fig. 1 shows examples of results obtained from the measurement of the thickness of sulfide scale at 900 and $800^{\circ} \mathrm{C}$. From these, the thickness of sulfide is proportional to the square root of time. Two layers were found in the scale as described later, and so the thickness was also plotted in this figure. In this case, the thickness of each scale shows again the same relation as above, and the outer layer is always thicker than the inner

one. From the above data, the growth-rate constant $k^{\prime}\left(\mathrm{mm} / \mathrm{hr}^{1 / 2}\right)$ of sulfide was calculated, and the Arrhenius plots for both kinds of cast iron was shown in Fig. 2. From the plots, Al-C.I. showed good resistance to sulfur attack, but it approached to that of M.C.I. at high temperature and a linear relation holds for M.C.I. The intersection of two curves was seen between $650 \sim 700^{\circ} \mathrm{C}$ for $\mathrm{Al}-\mathrm{C}$.I., and
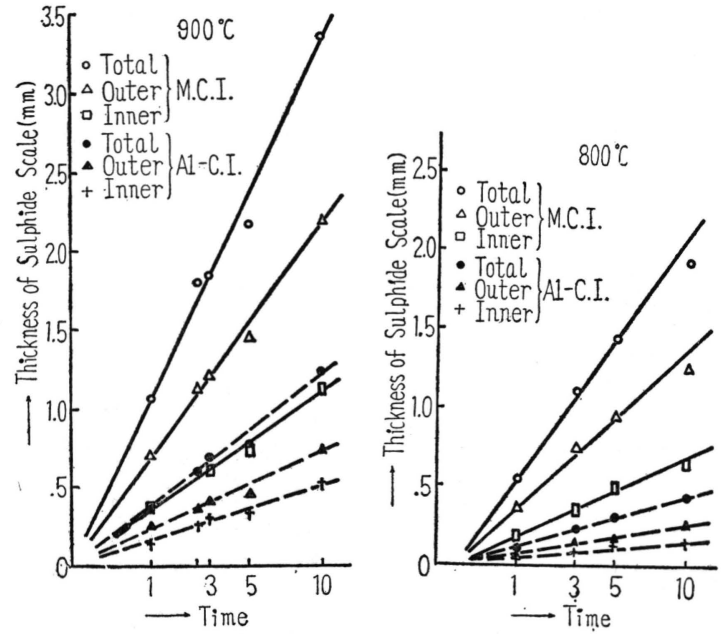

Fig. 1 The thickness of each layer of sulfide scale v.s. time curves.

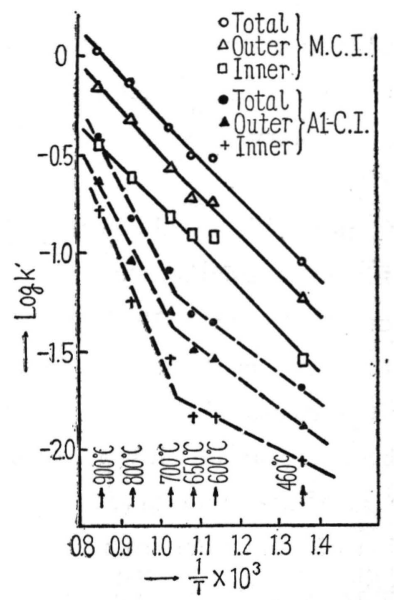

Fig. 2 Arrhenius plots for both kinds of cast iron.

* On the High-Temperature Corrosion of Iron and Steel Sulfur Vapor (Part 2).

** Muroran Institute of Technology, Hokkaido.

The original written in Japanese can be seen in J. Electrochem. Soc. Japan, 26. 650 (1958). 
the big inclination of the curve at high temperature would be attributed to the change of its structure (decomposition of cementite or graphitization).

(b) On the sulfide scale. The scale in both samples consisted of two layers as mentioned above. The inner layer was dense and yellowish grey, but the outer one was of coarse grain and metallic luster. Furthermore, other characteristics were observ ed as follows :

1) At the corner, the shape of outer scale was very different from that of the inner one. The former was scarecely thickened, while the latter was just the same with the prepared shape of sample (Photos. 1 and 2). Such phenomena were observed in other experiments ${ }^{(4)}$.

2) The distance between the outer surfaces of the inner layer of scale agreed with the prepared size of test pieces within $1 \sim 3 \%$ error.

3) The graphite flake was found only in the inner layer, and not in the outer layer, as seen in Photos. 3 and 4 . These flakes were primarily involved in sample, and were loosened into sulfide during the corrosion of a substrate (Photo. 5), so that these constituted a kind of marker.

From the above observations, the mechanism of sulfurization of cast iron would be as follows :

When Fe-ion migrates outward through the thin sulfide scale (FeS type), which was formed at first on the sample by chemical reaction, vacancies formed at the metal/sulfide interface form cavities or voids without migrating into metal. Accordingly the transfer of $\mathrm{Fe}$-ion would decrease.

In order to maintain the sulfurization of metal in these conditions, the thin scale itself would be close to the surface of substrate, otherwise sulfide ion should migrate inward through the scale.

When the sulfide scale is not thick enough, the former process will continue., For example, thickness of inner scale in carbon steel decreased with decreasing content of carbon ${ }^{(5)}$. But when the scale is thick enough or there are some obstacles to hinder the access of the scale (in the case of cast iron), sulfidation began to diffuse inward through the sulfide to the metal/ sulfide interface, and produced sulfide at that site with consumption of iron atom from the metal, and then filled up cavities. Subsequently iron ion continued again to migrate outward.

According to such a model, the thickness of each layer and the total thickness of both layers were formulated and found to submit to the parabolic rate law. The rate of thickness of outer layer to that of total sulfide was $1-\alpha$, where $\alpha=$ molar

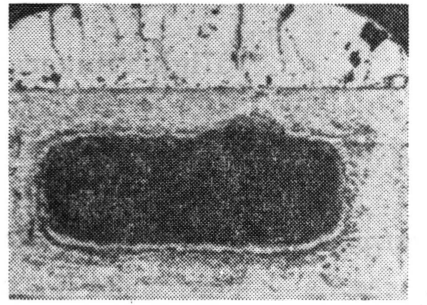

Photo. 1 The sectioned view of M.C.I. corroded at $900^{\circ} \mathrm{C}$ for $10 \mathrm{hrs}$. $\quad \times 4.3$

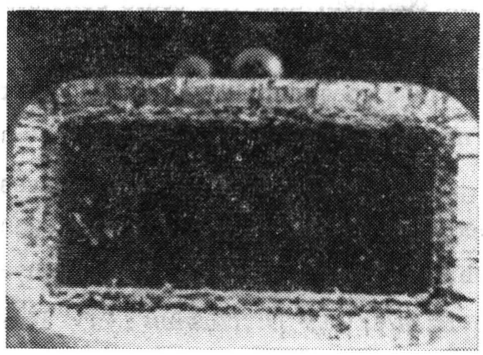

Photo. 2 The sectioned view of Al-C.I. corroded at $900^{\circ} \mathrm{C}$ for $10 \mathrm{hrs}$.

$\times 4.3$

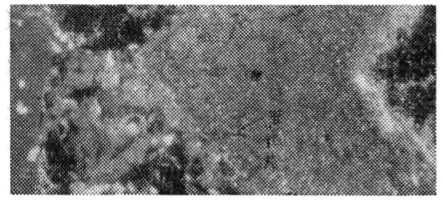

Photo. 3 The forms of two layers at corner of M.C.I. corroded at $800^{\circ} \mathrm{C}$ for $10 \mathrm{hrs}$ $\times 45$

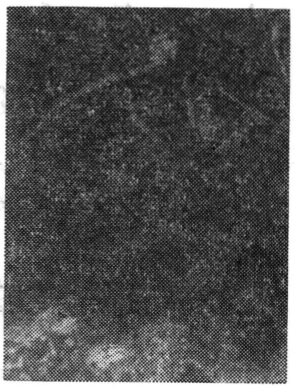

Photo. 4 The graphite in the inner layer of sulfide scale on M.C.I. corroded at $700^{\circ} \mathrm{C}$ for $12 \mathrm{hrs}$. $\times 125$ 
volume of iron/molar volume of iron sulfide (FeSo). At $800^{\circ} \mathrm{C}$ the calculated value (62.6\%) from the data of Meussner et al. for example was very close to the observed value $(66.5 \%$ for M.C.I. and $61.9 \%$ for Al-C.I.).

The shape of outer layer of scale at corner was also discussed from above mechanism. In Fig. 3 broken lines and solid lines show the calculated and observed shapes, respectively.

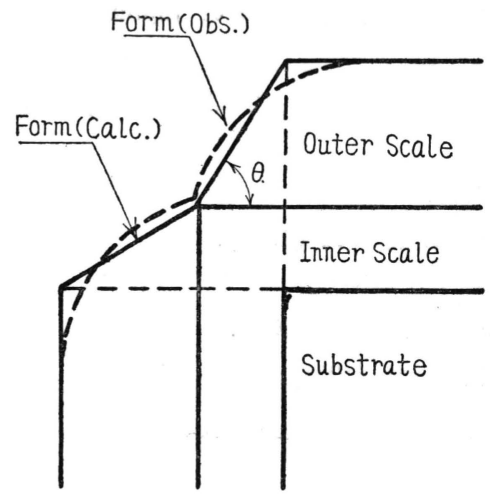

Fig. 3 The form of scale at corner (schematic).

As seen in the figure, those lines hardly agree with each other. This fact would be due to the expansion of outer scale at a free end to $\alpha<1$ and also to the contraction of molar volume of sulfide at the surface.

(c) The surface of outer layer of sulfide scale. It was reported that there are spinal growth patterns or loop steps on the surface of sulfide scale on armco iron. In this case the same patterns were also observed on M.C.I. (Photos. 6 and 7), but on Al-C.I. the rectangular plate-like crystals of not spirals were recognized (Photo. 8).

These patterns correspond undoubtedly with X-ray analysis for such scales. That is, the outer layer of M.C.I. has strongly diffracted ring from (001) planes. Therefore the scale of pyrrhotite orientates with (001) plane parallel to the surface of M.C. I. substrate. On the other hand, in the case of Al-C.I., it orientates with (110) plane of sulfide parallel to the substrate surface.

Note Just recently Dravnieks et al. ${ }^{(9)}$ reported the mechanism of sulfurization of low carbon steel in $\mathrm{H}_{2} \mathrm{~S}$ or $\mathrm{H}_{2} \mathrm{~S}$ and $\mathrm{H}_{2}$ atmosphere. Their conclusion agrees fairly with that pointedout here, although their sample and technical methods differed from those we used.

\section{Literature :}

(Received August 28, 1958)

(1) S. Shiozawa and H. Nakai : Report of the Castings Research Laboratory of Waseda University, 4, 17

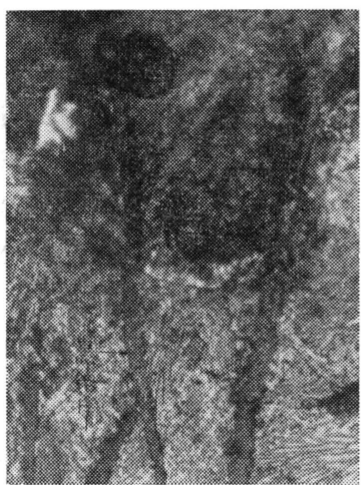

Photo. 5 The graphite flakes loosened into innerlayer of scale from substrate of M.C.I. corroded at $650^{\circ} \mathrm{C}$ for $10 \mathrm{hrs}$.

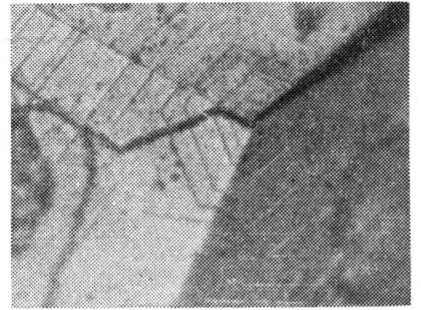

Photo. 6 The spiral growth pattern on the scale of $\mathrm{M}$. C.I. at $800^{\circ} \mathrm{C}$ for $10 \mathrm{hrs}$.

$\times 300$

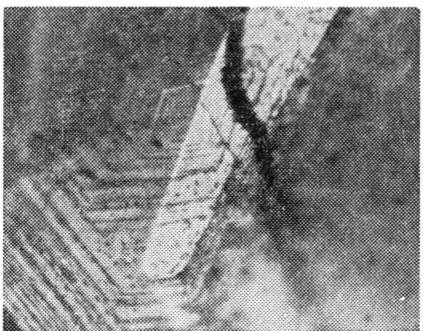

Photo. 7 Ditto. $\times 300$

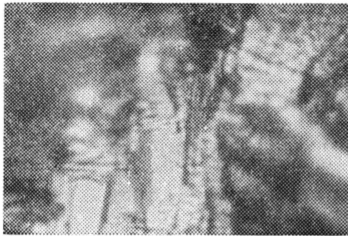

Photo. 8 The rectangular platelike crystals on the scale of Al-C.I. at $900^{\circ} \mathrm{C}$ for $10 \mathrm{hrs}$.

$\times 300$ 
(1953).

T. Murakami et al. : J. Japan Inst. Metals, 3, 131 (1939).

Y. Serida : J. Japan Foundryman's Soc., 30, 88 (1958).

H. Nakai and S. Shiozawa : J. Iron and Steel Inst. Japan, 42, 811 (1956) ; The 52 nd Symposium of Iron and Steel Institute of Japan.

(2) S. Shiozawa and H. Nakai : Report of the Castings Research Laboratory of Waseda University, 5, 11 (1954).

(3) K. Nishida and H. Oikawa : Reprint for the 42nd Symposium of Japan Institute of Metals, p. 26 (1958).

(4) K. Nishida : Memoirs of Muroran Institute of Technology (Hokkaido, Japan), 2, 173 (1957).

(5) K. Nishida : Unpublished report.

(6) R.A. Meussner et al.: Corrosion, 13, 79 (1957).

(7) G. Hägg and I. Sucksdorff : Z. physik. Chem., B 22, 444 (1933).

H. Haraldsen : Z. anorg. Chem., 246, 169 and 195 (1941).

(8) K. Nishida and S. Koda : Metal Physics, Japan, 2, 166 (1956).

(9) A. Dravnieks et al. : J. Electrochem. Soc., 105, 183 (1958). 